\title{
USE OF GEODESY MATERIALS IN BIKE ORIENTEERING MARATHONS
}

\author{
Przemysław Baster
}

\begin{abstract}
Summary
The increase in the number of bike orienteering marathons in recent years in Poland has encouraged search for interesting terrains for races that would promise increasingly exciting competitions. In consequence, the significance of various geodetic materials during competition also grows. The type of used maps depends on the length of a race, communication system and the diversity of geological features and land cover. Proper reading of information contained on the maps by the organizers and competitors allows not only to identify an optimal route and find checkpoints, but also to reach monuments worth discovering. Such a presentation of cultural heritage - including the smallest, the most underestimated or forgotten landscape forms - is possible thanks to the ability to use existing maps combined with good orientation in the field.
\end{abstract}

\section{Keywords}

maps $\bullet$ geodesy $\bullet$ orienteering competitions $\bullet$ sense of direction $\bullet$ orienteering $\bullet$ cultural heritage

\section{Introduction}

Races have a very long tradition both in Poland and across the world. Their history runs back to the Olympic Games in ancient Greece, and since then were regarded as one of basic sport disciplines. Today they are organized not only as part of sports competitions, but also in an increasingly popular form of mass events which do not require any special skills, e.g. marathons and memorial half marathons. The route is same for everyone and marked out in a field by the service. All bike marathons follow similar rules - the winner is the first to reach the finish line after a fixed route.

This form of sports rivalry does not satisfy everyone, as some perceive the necessity to follow a strictly defined route, in a group of competitors or peloton as a limitation. For this reason people came up with the idea of organizing orienteering competitions, which not only respond to the decline in physical activity of the society, loss of contact with the natural environment and little knowledge of a broadly understood cultural heritage of Poland. They also create an opportunity to combine physical and intellectual effort, consisting of independent movement between designated checkpoints in an unknown area with a support of a map. Thus, orienteering competitions have 
no strict distance that has to be covered. The person - who checks in at the largest possible number of stations - wins, not the one who reaches first the finishing line. The ranking is firstly based on the sum of points collected, and only if their number is equal, the time to reach the finish is taken into account [Mroczyński and Hirsz 1992, Trzmielewski 1992, Cegiełka and Sierzputowski 2008].

The first orienteering races were organized at the end of the 19th century in Scandinavia. They gained popularity after World War II; in 1950 the first competition took place in Czechoslovakia, and three years later in Germany. Gradually, new disciplines of orienteering sports appeared: ski orienteering, bike orienteering and orienteering marathons [Mroczyński and Hirsz 1992, Trzmielewski 1992, Cegiełka and Sierzputowski 2008]. In the Polish Cup of Bike Orienteering Marathons, the number of organized events has increased from several to several dozen over the past ten years.

\section{Purpose and methods}

The paper aims to present the application of geodesy in bike orienteering marathons. Particular types of maps and ways of using their data are determined for usefulness in various conditions and for finding optimal locations for checkpoints ${ }^{1}$.

The information presented is an effect of several years of in situ tests carried out during dozens of bike orienteering marathons, also based on map analysis, environmental survey and interviews with competitors. The basic rules for these marathons were combined with a description of the maps and practical experience in using them during the competitions.

\section{Research status}

The subject area presented in the paper is not yet comprehensively developed. The topic of orienteering is raised in existing publications in general and with respect to various specific aspects: orienteering competition principles [Mroczyński and Hirsz 1992, Trzmielewski 1992, Cych 1997], application of orienteering for military purposes and increasing the efficiency of operations [Accles 2008], methodology of work with children [Ruzicka 2015], improving methods of physical training of competitors [Sirakov and Belomazheva-Dimitrova 2018], impact of orienteering on the general physical and mental development of youth [Vaskan at al. 2019].

As bike orienteering marathons are only gaining popularity in Poland, the paper is intended to fill the scarcity of concerning them scientific publications. The paper is the first scientific publication describing a variety of maps used in bike orienteering marathons, also in terms of making competitions more attractive and extending the choice of routes by competitors. It describes in an innovative approach the differences between the way geodetic materials are used in bike orienteering marathons and in other orienteering competitions.

1 The author has been a participant of bike orienteering marathons and competitions for several years, classified annually in the Polish Cup in Bike Orienteering Marathons. 


\section{Discussion}

\subsection{The validity of using different maps in orienteering competitions}

All competitions that require understanding of terrain are inextricably linked to geodesy. Each competitor chooses her own route to the finishing line with an aid of a map and a compass. There are no signs, arrows, direction indicators, peleton, helpers during a race. This sport requires not only a very good physical condition, but also an intellectual ability, concentration and self-control. Having different maps, competitors need to make quick decisions about the best possible routes when running in unknown terrain at high speed. The race results therefore depend on the combination of all - physical, technical, psychological, tactical preparation, but also largely on the ability to read data from geodetic materials [Sirakov and Belomazheva-Dimitrova 2018]. The organisers do not delineate a fixed route, meaning that there have to be checkpoints, which the competitors can reach only with a compass and maps made available before the start (without prohibited GPS satellite navigation systems).

The differences between the various types of orienteering (foot and bike competitions, as well as foot and bike marathons) open a wide range of possibilities of available geodetic materials, formats and scales, as well as ways to utilise them. Various distances require maps of different scales, while different speeds of motion during competition, as well as geological features and terrain cover determine the type of maps and the location of checkpoints. There are completely different ways for competitors to learn about the most interesting landscape forms and region's cultural heritage. Generally, the greater the distance, the less accurate the maps, the easier is finding checkpoints and the greater are possibilities of displaying elements of cultural heritage [Mroczyński and Hirsz 1992, Trzmielewski 1992, Cegiełka and Sierzputowski 2008].

\subsection{Map scales used in bike orienteering marathons}

The map scales used in bike orientation marathons depend mainly on the estimated distance and the degree of diversity of geological features in a given area. Currently, in Poland, cup races are organized for 100-300 kilometres (by the shortest route between checkpoints on existing paths and roads); sometimes an additional short route of several dozen kilometres is delineated. The basic topographic maps distributed at the start are usually in A4 or A3 format, which is suitable for the scales 1:50,000 or $1: 100,000$ in cup races and $1: 50,000$ in short races. This is very different from orienteering and bike orienteering maps, which cover shorter distances (from several to several dozen kilometres) and need more accurate maps.

Calculating the simplest distances: 1 millimetre on a map on a scale of $1: 50,000$ corresponds to 50 meters, and on a scale of $1: 100,000$ up to 100 meters. It is very difficult to measure a distance of less than 1 millimetre on a paper map, so in when a distance of 100 meters is too large to find a checkpoint, in addition to the basic map, so called 'highlights' are attached. These are small maps magnifying the location of a checkpoint together with its vicinity; they are usually made on a scale of $1: 20,000$, 
$1: 10,000,1: 5,000$, regardless of the distance (for a detailed description and examples of 'highlights' - see Fig. 3a, b, c, d).

\subsection{Using maps to locate checkpoints in bike orienteering marathons}

At checkpoints competitor confirms his presence electronically or by a start card. In the field, these are white-orange lanterns or A4 cards of the same colour. The map is marked by a red circle with a centre indicating the exact location of a checkpoint [Mroczyński and Hirsz 1992, Trzmielewski 1992, Cegiełka and Sierzputowski 2008]. To enable finding checkpoints in the most difficult places, in addition to markings, the map also provides written information about (near what element of a landscape) their location.

The location of checkpoints should serve not only as a simple statement of fact of reaching an accidentally selected spot located at a specific distance from the start/finish. Such mere confirmation of reaching a particular distance would simply repeat what is the essence of an ordinary marathon. In bike orienteering marathons of particularly significance is the variety of checkpoint locations, because, unlike orienteering and bike orienteering, they mostly take place in the form of so called 'scorelauf'. This means that there is no fixed order of arriving at checkpoints - it is the competitor who decides which point will be reached earlier and which later. When the order of checkpoints is determined, the routes of individual competitors are very similar, and it is easy for the organizers to predict. Even before the start, it is known approximately which routes most competitors will follow and what they will see along the way. This is very difficult to anticipate in bike orienteering marathons - its aim is even to create as many routes as possible. In this regard, only diverse locations of checkpoints guarantee a variety of visited landscapes with different geological features (Fig. 1a, Fig. 1b).

Therefore, by browsing maps with marked checkpoints and comparing their descriptions made available at different marathons, a huge variety of selected elements and landscape forms can be noticed as places of checkpoint locations. Regardless of the terrain of a competition, they are set in all possible areas, forms of land cover and geological features, including:

- urbanised, open and green landscape,

- architectural and nature monuments,

- public places, near main traffic routes, as well as far from them, where cycling is very difficult,

- areas with a huge variety of small forms, as well as vast, regular areas.

In addition to learning about cultural heritage, due to such locations of checkpoints the competitors can test their physical, navigational and geodetic skills. The distance and the speed mean that not only endurance and strength is required to drive on different surfaces and terrain, but also finding the optimal route in different landscapes, as well as quick reading of information from the maps on land use with completely different functions and structure, and finally then excellent sense of directions. 


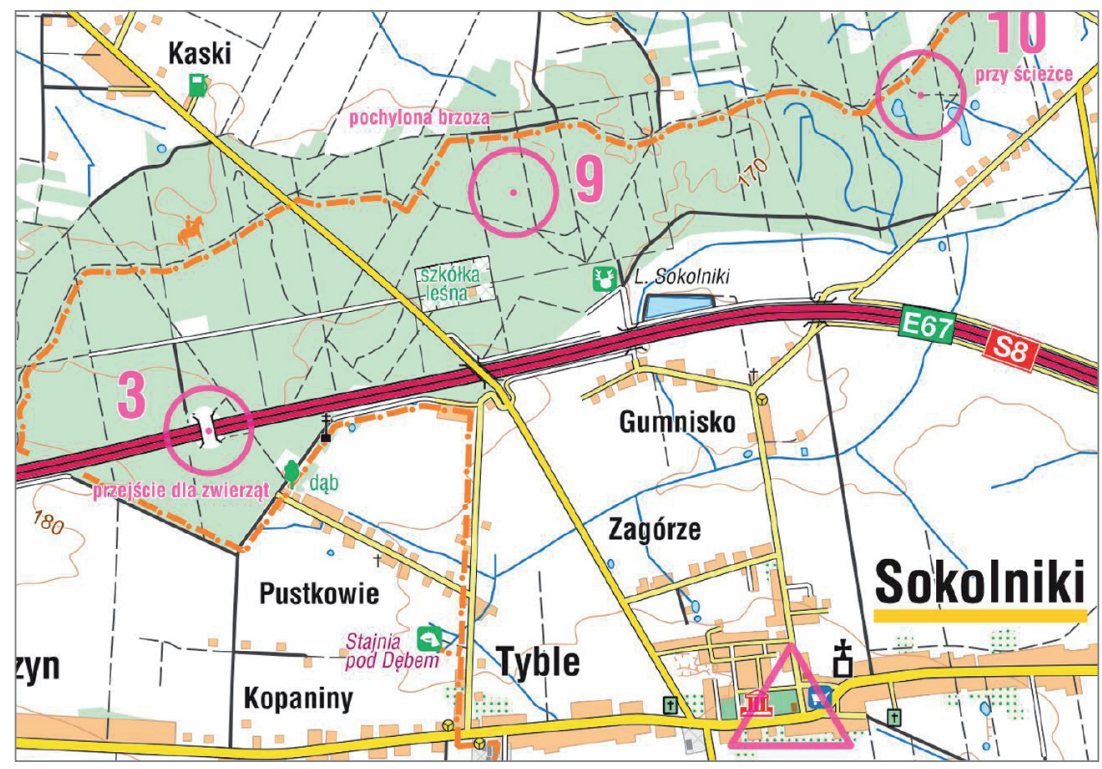

Fig. 1a. A fragment of a topographic map with marked checkpoints. Original scale $1: 50,000$. Map made by COMPASS s.c. Specifications: Piotr Banaszkiewicz

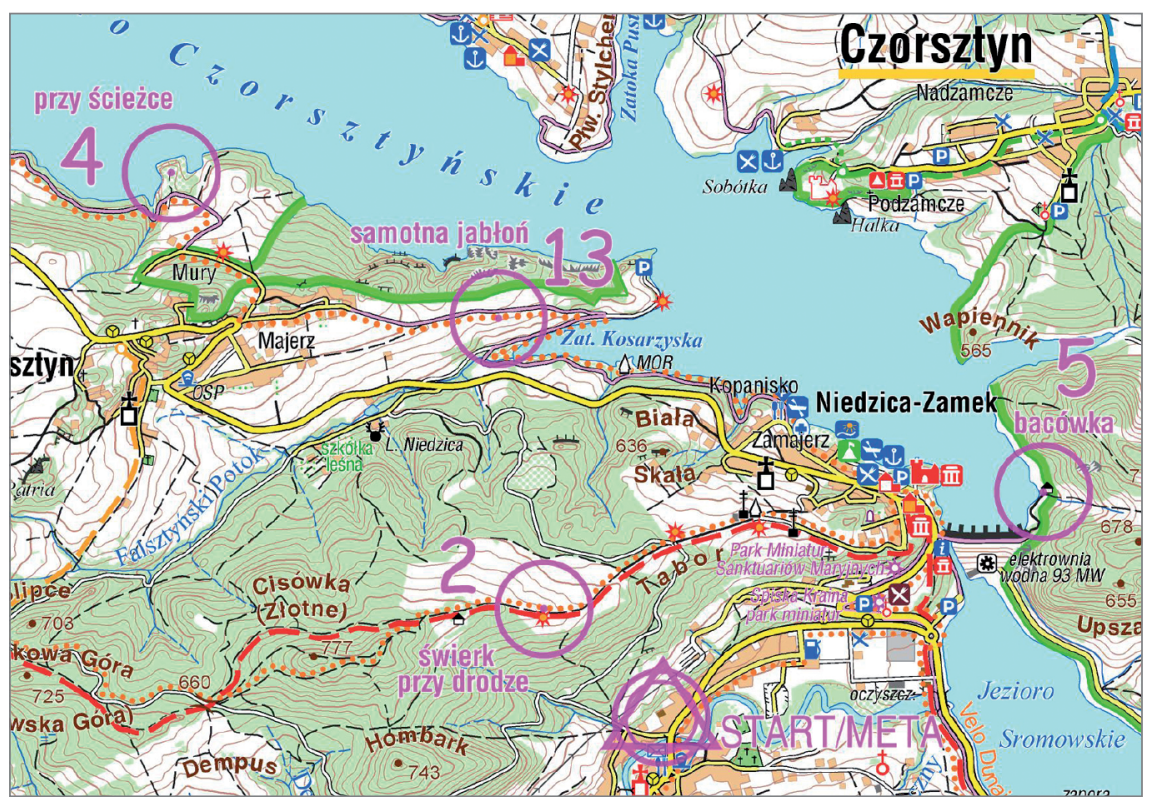

Fig. 1b. A fragment of a topographic map with marked checkpoints. Original scale $1: 50,000$. Each variant from each checkpoint to point 5 ensures that competitors see the castle and the dam in Niedzica. Map made by COMPASS s.c. Specifications: Piotr Banaszkiewicz 


\subsection{The use of maps for displaying cultural heritage during bike orienteering marathons}

In bike orienteering marathons, it is necessary to travel long distances independently, thanks to which competitors can observe many valuable elements of a landscape and admire its richness of forms and views. Even at distances of several hundred kilometres and time limits of many hours this form of orienteering allows competitors to choose between a fast route or one full of interesting places and geological features. For this reason, orienteering popularises both cultural heritage and beauty of landscapes of Poland, from the largest renowned monuments to the smallest forms, which are unknown even to the local community. Local residents rarely come around most of the uninhabited area of their village. The use of maps and thoughtful location of checkpoints allows competitors to reach these sites. Very often these sites are distant from the main communication routes, where it can only access using a variety of updated geodetic maps.

Therefore, the main challenge of the persons responsible for setting up control points (so called route planners) is to arrange for marathon participants the most interesting landscapes. Optimal location of checkpoints displays both the most famous architectural monuments and the smallest natural forms. Competition continuously exhibit, among others:

- architecture: manors, palaces, court buildings, churches, but also old mills, homesteads, pens, etc.,

- small architecture and engineering structures: monuments, memorials, bunkers, artillery stands, fortifications, roadside chapels, individual graves and bridges, but also footbridges and culverts,

- nature:

- all forms of historical and contemporary composed greenery (including witness trees, symbolic trees), but also the most interesting plant specimens, cultural boundaries, and tree stumps,

- water elements visible from afar, but also almost inaccessible fragments of banks of streams, lakes, ponds and ditches,

- differences in land height, including inaccessible scarps, slopes, overhangs, cliffs with their land cover elements, as well as excavations, anti-tank ditches or other post-war basins.

- viewpoints and spots of panorama exposition.

A special way to present cultural heritage during bike orienteering marathons is designating the so called 'special stages' (SS). It is a short route drawn on a map with a continuous line (several hundred meters to several kilometres long), without fixed control points (from one to several). The racer, wanting to collect these checkpoints, must drive the entire designated special stage - exactly as shown in the map. The organizers can rest assured that the competitors will see all the elements of the landscape situated along the route. Moreover, they will see them precisely, as searching for hidden 
control points will move at a slower speed than usual. Therefore, SS is set in a particularly beautiful area, e.g. along charming meanders of a river or a stream, or a top of hill, from where a panorama stretches (Fig. 2).

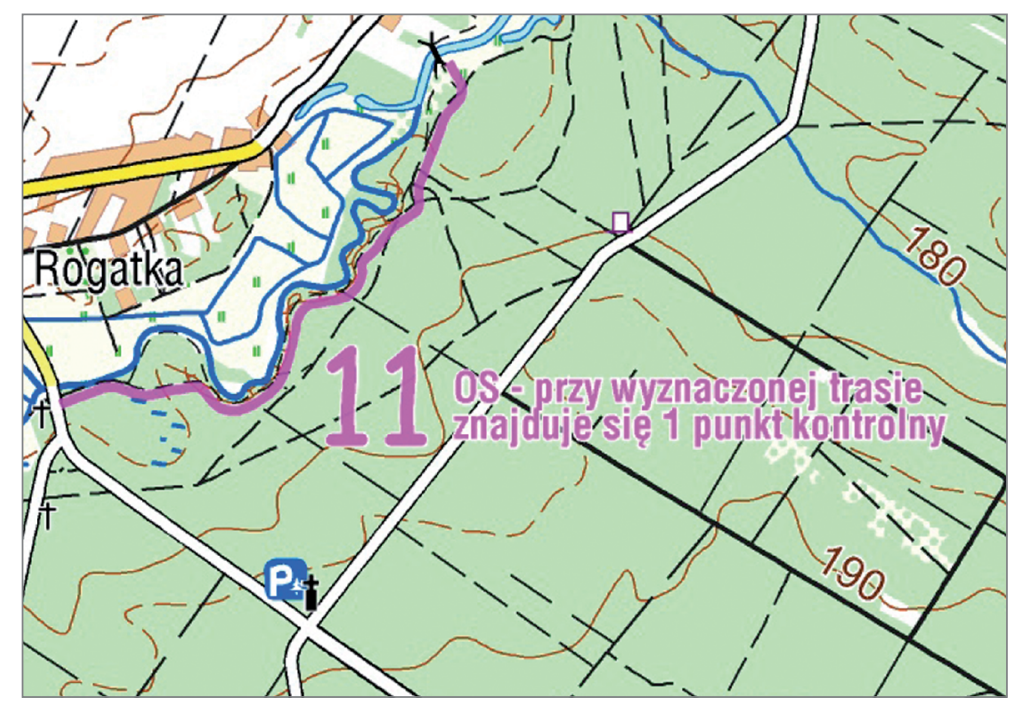

Fig. 2. A fragment of a topographic map with the SS 'Special Stage' marked along the stream and displaying the beauty of its meanders. Original scale: $1: 50,000$. Map made by COMPASS s.c. Specifications: Piotr Banaszkiewicz

Thanks to the above, bike orienteering marathons provide unique aesthetic values and knowledge of the area. During organized tourist and sightseeing trips, usually only the most important monuments and objects or flora located on the main routes, roads and paths are seen. During hiking 'trips into the unknown' and orienteering, you can find less known sites, but in a small area. When cycling, the speed of travelling over a relatively small area and short distance does not facilitate contemplation of the beauty of a scenery. Bike orienteering marathons, on the other hand, allow competitors to familiarize themselves with a very large number of valuable parts of landscape located throughout a large area.

\subsection{A variety of maps used during bike orienteering marathons}

Knowledge of geodesy, comparing the information from maps to reality and navigation skills in a huge area are irreplaceable in this discipline. The variety of routes chosen increases the importance of information contained in geodetic materials. Any seemingly trivial information / sign may change the route variant. In the case of bike orienteering marathons, placing proper information / signs on a map and reading them by the competitor is particularly important, because an error can sometimes translate into 
a few or several additional kilometres and a loss of many valuable minutes. Therefore, it is often necessary to use as many as several maps, which, when combined, give only a full picture of different variants of the right course. At the same time, competitors must be aware that due to the extent of mapped area, the maps are only updated at checkpoints with details or 'highlights'.

At a checkpoint located in an urbanized cultural landscape, in a public space, next to a large building, it is usually enough to 'glance' at the map to find it. The importance of updated maps increases when a checkpoint is in a completely different location - with unknown, hidden elements of the landscape, outside of the urbanized area. Paradoxically, the greatest navigation difficulties are caused by both inaccessible areas with a large variety of landscape forms, as well as vast, regular areas. It is very difficult to find a lantern both in the middle of the woods and in the middle of a 'forest nursery' planted in a chequerboard pattern. Then the control points can be found by considering several types of data read from the map, e.g. distance from other noticed forms of landscape, differences in height of the terrain (levels), communication system, land cover. In this case, the basic topographic map illustrating the entire competition area may not be sufficient. The abovementioned 'highlights' are then used, allowing for a more precise determination of a checkpoint whose location based on a topographic map $1: 50,000$ or $1: 100,000$ would be practically impossible to pinpoint.

In orienteering marathons any map can be 'highlighted' - it depends on the shape and cover of the mapped area. Of course, the more inaccessible these places are, the more important it is to have a map that is 'highlighting' this place. Usually, orthophotomaps, topographic maps adapted to bike orienteering and orienteering are used, and sometimes even LIDAR maps or historical maps (sic!). The specificity of individual maps and the type of information they contain is closely related to the way they are used.

The orthophotomap, which is essentially a top-down view that maintains proportions and scale, works well when locating points on flat terrain with a small number of buildings. It is marked with points set near the elements of landscape visible from the bird's eye, and hardly accessible or difficult to find in the field, such as: small glades, firebreaks and cultural boundaries in a forest, as well as groups of trees and groves growing among fields or meadows (Fig. 3a).

Topographic maps adapted to orienteering are often prepared for areas with many roads and paths, a large variety of terrain forms and a significant variation in terrain height. Special markings for the traffic system are used in these maps; a distinction is made between the widths of communication routes and the speed at which they can be travelled. The boundaries and types of landscape forms are clearly defined. A dense contouring cut (from 2.5 to 10 meters) is assumed. Due to these features, these maps are a support in the field, where the most crucial for finding a control point are differences in heights in relation to the traffic system and distinctive landscape forms. We are talking about points located in a dense network of roads and paths, on rocks, on scarps, on steep slopes, over cliffs, on the banks of rivers flowing in canyons and valleys, in anti-tank ditches or among many hills and depressions (Fig. 3b). Irregularities and differences in terrain height in these forms of the geological features speak for the use of 

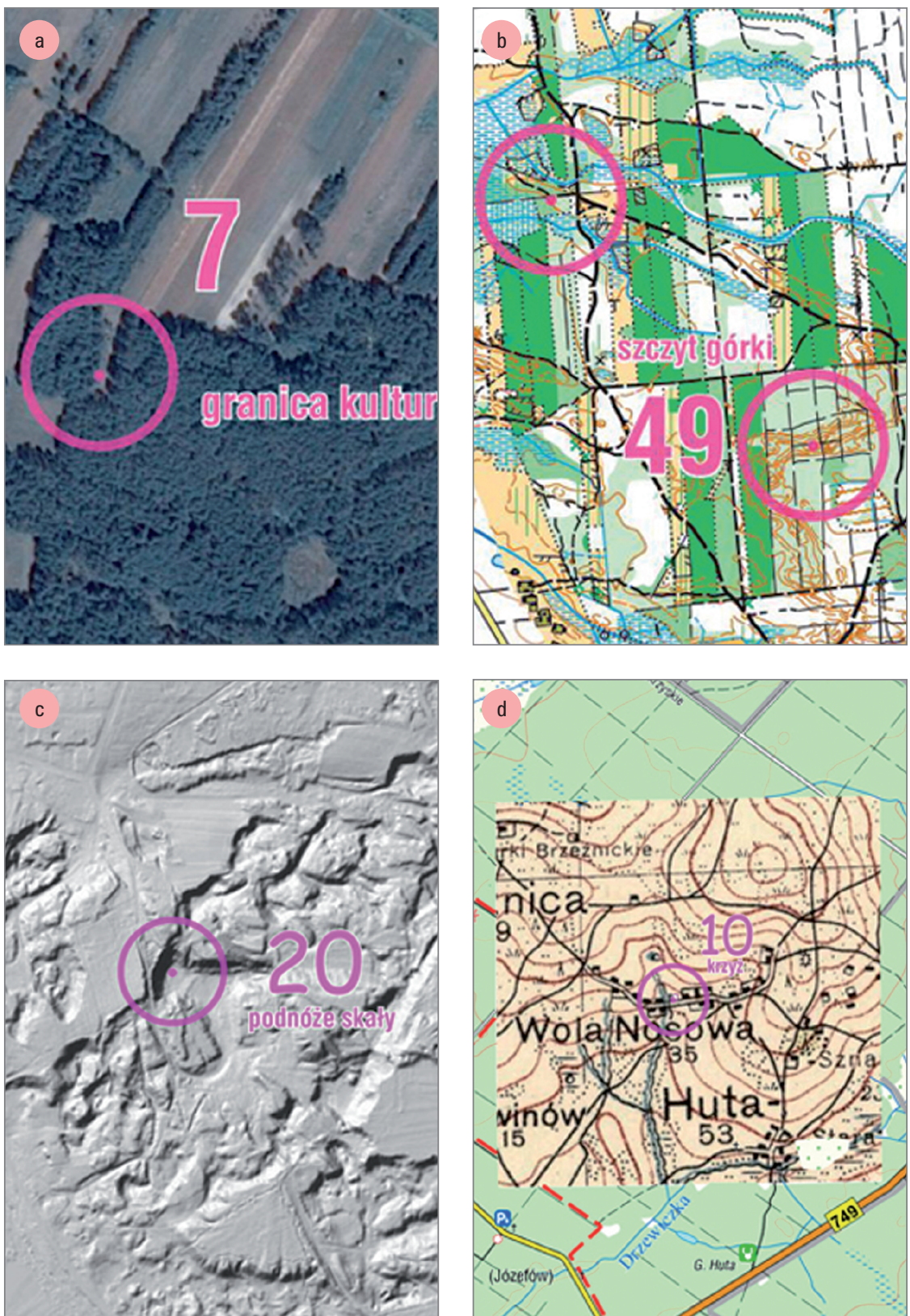

Fig. 3. 'Highlights' of a checkpoint. Specifications: Piotr Banaszkiewicz (rows, from above). 3a. Orthophotomap, scale of the original 1 : 5,000, source: www.geoportal.gov.pl, fragment of the map made by COMPASS s.c. 3b. Map adapted for orienteering, scale of the original $1: 10,000$, map made by COMPASS s.c. 3c. Map made using the LIDAR technique, source: www.geoportal.gov.pl. 3d. Historical topographic map from the interwar period 
highlights made by the LIDAR technique (Fig. 3c). Historical maps are a unique form of 'highlighting. They can be utilised, for example, in places where entire towns were destroyed during World War II, and a checkpoint is next to the surviving elements: crosses, orchards, etc. Such a map is a great picture of historical transformations and a silent lesson in the history of this area (Fig. 3d).

\section{Conclusion}

Reading information from various maps is an essential skill in bike orienteering marathons. Constant analysis of data contained in geodetic materials while driving allows to find not only checkpoints, but also many valuable landscape forms. It enables learning about important elements of cultural heritage, and even spatial solutions, of which location in the field is often an invaluable clue when determining the further route. During very difficult competitions several types of maps of different scales are needed, which requires of competitors to constantly carry out comparative analysis and to combine skills in geodesy, topography, planning and photogrammetry.

\section{Acknowledgements}

Thanks to Roman Trzmielewski for permission to publish fragments of maps issued by COMPASS sc. Thanks to the Technical Judge of the Polish Cup in Bike Marathon Orienteering Jarosław Wieczorek and to the organizers, route planners and leaders of the general classification of the Polish Cup of Bike Orienteering Marathon, who gave me a lot of valuable information used in this article: Piotr Banaszkiewicz, Maciej Konopiński, Grzegorz Liszka, Paweł Cichoń, Łukasz Mirowski, Wojciech Hołdakowski, Radosław Walentowski, Mateusz Pach.

\section{References}

Accles D. 2008. Experts' Circumvention of Processing Limitations: An Example From the Sport of Orienteering. Military Psychology, Supplement 1, 20, 103-121.

Cegiełka J., Sierzputowski P. 2008. Rowerowa jazda na orientację. Polski Związek Orientacji Sportowej, Warszawa, 1-2, 5-7.

Mroczyński Z., Hirsz M. 1992. Bieg na orientację, vol. 1. Wydawnictwo Uczelniane AWF, Gdańsk, 4-10.

Ruzicka I. 2015. Longitudinal monitoring of performance in crosscountry running by young orienteering runners. Journal of Human Sport \& Exercise, Special Issue, 10, S269-S278.

Sirakov I., Belomazheva-Dimitrova S. 2018. Value of technical trainings, their analysis and effects on the preparation process of world elite orienteering competitors. Journal of Physical Education \& Sport, Supplement, 18, 2127-2133.

Trzmielewski R. 1992. ABC biegu na orientację. Krakowski Okręgowy Związek Orienteeringu, Kraków, 3-17.

Vaskan I., Koszura A., Kurnyshev Y., Moseychuk Y., Tsybanyuk O., Yarmak O., Galan Y. 2019. Orienteering in the system of recreational and health-improving activity of student youth. Journal of Physical Education \& Sport, Supplement, 19, 489-494. 
Dr inż. arch. Przemysław Baster Uniwersytet Rolniczy w Krakowie Katedra Geodezji Rolnej, Katastru i Fotogrametrii 30-198 Kraków, ul. Balicka 253a

e-mail: pbaster@ar.krakow.pl 